\title{
PERAN MEDIASI CUSTOMER SATISFACTION DALAM CUSTOMER EXPERIENCE DAN LOYALITAS PELANGGAN
}

Submitted Date :

15 September 2020

Accepted Date :

25 November 2020
Demak Claudia Yosephine Simanjuntak

Universitas Prima Indonesia

claudiayoseph8@gmail.com

Purnama Yanti Purba

Universitas Prima Indonesia

purnama.js@gmail.com

\section{Suggested Citation:}

Deng, Z., Lu, Y., Wei, K.K., and Zhang, J. (2010). Understanding Customer Satisfaction and Loyalty: An Empirical Study Of Mobile Instant Messages In China . International Journal of Information Management, 30(4), 289-300.

Abstract:

This study aims to examine the effect of customer experience and customer satisfaction on customer loyalty and whether customer satisfaction mediates the relationship between customer experience and customer loyalty. The data analysis method used is structural equation modeling-partial least squares (SEM-PLS). The number of respondents is 150 people. Sampling technique of this study is quota sampling method. The study shows that customer experience has a positive and significant effect on customer loyalty, customer experience has a positive and significant effect on customer satisfaction, and customer satisfaction has a positive and significant effect on customer loyalty. By conducting mediation testing, it is concluded that customer satisfaction is significant as a mediator of the relationship between customer experience and customer loyalty.

Keywords: Customer Experience, Customer Loyalty, Customer Satisfaction

Abstrak:

Penelitian ini bertujuan untuk menguji pengaruh customer experience dan customer satisfaction terhadap loyalitas pelanggan dan apakah customer satisfaction memediasi hubungan customer experience terhadap loyalitas pelanggan Metode analisis data yang digunakan adalah structural equation modeling-partial least squares (SEM-PLS). Jumlah responden adalah 150 orang. Teknik pengambilan sampel dalam penelitian ini dengan metode quota sampling. Hasil penelitian menemukan bahwa customer experience berpengaruh positif dan signifikan terhadap loyalitas pelanggan, customer experience berpengaruh positif dan signifikan terhadap customer satisfaction, dan customer satisfaction berpengaruh positif dan signifikan terhadap loyalitas pelanggan. Dengan melakukan pengujian mediasi, disimpulkan bahwa customer satisfaction signifikan sebagai pemediasi hubungan antara customer experience terhadap loyalitas pelanggan.

Kata Kunci: Customer Experience, Customer Satisfaction, Loyalitas Pelanggan

JEL Classification: I29; M31. 


\section{Latar Belakang}

Pendidikan adalah sesuatu yang penting dalam kehidupan manusia. Presiden Joko Widodo menegaskan pentingnya pendidikan dalam meningkatkan Sumber Daya Manusia (SDM). Pendidikan yang bagus, baik yang formal maupun non formal, akan menguatkan daya saing bangsa Indonesia dalam menghadapi kompetisi dengan negara lain yang lebih maju. Karena itu pendidikan harus ditempuh sepanjang hayat untuk meningkatkan kualitas sumber daya manusia. Selain pendidikan formal yang perlu ditingkatkan, pendidikan non formal juga perlu diperhatikan (www.edukasi.sindonews.com). Dalam UU pasa 4 no. 23 tahun 2003, menyebutkan bahwa pendidikan nasional bertujuan mencerdaskan kehidupan bangsa dan mengembangkan manusia Indonesia yang seutuhnya, yaitu manusia yang beriman dan bertaqwa kepada Tuhan yang Maha Esa dan berbudi pekerti luhur, memiliki pengetahuan dan keterampilan, kesehatan jasmani dan rohani, kepribadian yang mantap dan mandiri serta rasa tanggung jawab kemasyarakatan dan kebangsaan. Untuk mencapai tujuan tersebut, maka pendidikan dapat dilakukan baik secara formal maupun non formal. Para pelaku bisnis melihat hal ini sebagai peluang usaha yang menjanjikan. Dewasa ini persaingan di dunia usaha jasa pendidikan non formal semakin meningkat termasuk usaha bimbingan belajar sehingga menciptakan suatu persaingan yang kompetitif. Berdasarkan data Sensus Ekonomi 2016 oleh Badan Pusat Statistik, jumlah lembaga kursus dan pendidikan mencapai 619.947 unit, dan 1.866 unitnya adalah lembaga bimbingan belajar, menjadikannya termasuk paling populer, bersaing dengan lembaga kursus komputer (www.bps.go.id).

Ganesha Operation adalah salah satu perusahaan yang bergerak di bidang jasa pendidikan non formal. Perusahaan ini memberikan bimbingan belajar kepada anak SD, SMP, dan SMA. Sebagai salah satu perusahaan di bidang jasa, Ganesha Operation akan terus berusaha mencapai tujuan perusahaan dengan menciptakan pengalaman yang menyenangkan bagi pelanggannya yaitu para pelajar. Pengalaman yang menyenangkan saat proses belajar di Ganesha Operation Medan dapat menjadi pengalaman positif yang tak terlupakan oleh pelajar. Diharapkan dari pengalaman tersebut pelajar mampu membedakan produk dan jasa dengan pesaing bimbingan belajar lainnya. Menurut Terblanche (2009), customer experience sebagai akumulasi dari semua kejadian yang disadari oleh pelanggan. Bentuk pengalaman pelanggan yang menyenangkan menimbulkan kepuasaan pelanggan (customer satisfaction). Pelanggan yang puas dapat dilihat dari kesenangan atau kekecewaan berdasarkan hasil yang dirasakan dari produk atau jasa, apakah sesuai dengan yang diharapkan oleh pelanggan. Penilaian kepuasan para pelajar bimbingan belajar Ganesha Operation Medan dapat dirasakan oleh mereka melalui harapan peningkatan prestasi belajar.

Para pelajar mendapatkan pengalaman pribadi yang menyenangkan dan merasa puas akan menjadi pelanggan yang loyal di Ganesha Operation Medan. Sehingga loyalitas pelanggan dipengaruhi faktor diantaranya pengalaman pelanggan (customer experience) dan kepuasan pelanggan (customer satisfaction). Dalam kaitannya dengan pengalaman pelanggan dan kepuasan pelanggan. Menurut Sangadji (2013), loyalitas pelanggan tidak bisa tercipta begitu saja, tetapi harus dirancang oleh perusahaan. Oleh karena itu, perusahaan-perusahaan baik produk maupun jasa selalu merancang untuk memberikan pengalaman terbaik yang akan diingat dan dirasakan oleh pelanggan sehingga berdampak pada kepuasan pelanggan dan akhirnya pelanggan loyal terhadap jasa yang ditawarkan oleh perusahaan tersebut.

Peneliti tertarik meneliti di Ganesha Operation dikarenakan dewasa ini perusahaan mengalami perkembangan yang pesat. Ganesha Operation sudah tujuh tahun berturut-turut raih penghargaan Top Brand for Teens dan Kids sebagai bimbingan belajar terpercaya pilihan masyarakat di Indonesia . Sejak tahun 2010 sampai tahun 2019, siswa Ganesha Operation di berbagai daerah di Indonesia juga meraih nilai Ujian Nasional tertinggi. Selain itu Ganesha Operation telah tumbuh bagai remaja tambun dengan 788 outlet yang tersebar di 272 kota besar se-Indonesia. Hal tersebut membuktikan bahwa Ganesha Operation adalah bimbingan terbaik dan terbesar di Indonesia. Di kota Medan sendiri memiliki unit sebanyak tujuh belas yang menyebar ke seluruh kota Medan. Jumlah siswa-siswa yang belajar di kota Medan juga bertambah setiap tahunnya.

Peneliti mendapati fenomena bahwa pada umumnya yang menjadi siswa Ganesha Operation di IX SMP adalah siswa lanjutan Ganesha Operation dari kelas VIII SMP begitu juga dengan siswa SMA yang pada umumnya adalah lanjutan dari siswa SMP, bahkan ada yang sudah tiga sampai lima tahun sudah menjadi siswa Ganesha Operation. Peneliti mengindikasi hal-hal tersebut dapat terjadi oleh karena pelanggan mengalami sendiri bagaimana 


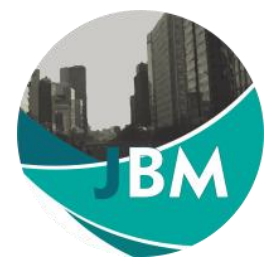

pelayanan jasa yang ditawarkan dan pelanggan puas terhadap kualitas pelayanan yang diberikan. Hal tersebut menimbulkan loyalitas pelanggan terhadap bimbingan belajar Ganesha Operation.

Dirbawanto (2016) menyarankan agar dapat mengembangkan variabel loyalitas pelanggan. Oleh sebab itu peneliti mengembangkan variabel loyalitas pelanggan pada perusahaan yang bergerak di bidang jasa pendidikan. Selain itu, hasil penelitian sebelumnya juga melatarbelakangi penelitian ini, dimana penelitian (Subagio, 2012) menemukan bahwa kepuasan berpengaruh terhadap loyalitas konsumen pada Garuda Indonesia. Peneliti tertarik bilamana kepuasan pelanggan berpengaruh di bidang jasa pendidikan bimbingan belajar.

Berdasarkan alur pemaparan dan uraian di atas, maka penelitian ini bertujuan mengetahui pengaruh customer experience dan customer satisfaction terhadap loyalitas pelanggan dan apakah customer satisfaction memediasi hubungan customer experience terhadap loyalitas pelanggan pada Ganesha Operation Medan. Hasil penelitian ini diharapkan dapat bermanfaat bagi Ganesha Operation Medan dalam memperhatikan dan meningkatkan yang berkaitan dengan customer experience, loyalitas pelanggan, dan customer satisfaction. Serta bagi peneliti selanjutnya, hasil penelitian ini dapat menambah wawasan dan menjadi rujukan apabila akan melakukan penelitian berkaitan customer experience, loyalitas pelanggan, dan customer satisfaction.

\section{Kajian Literatur}

\section{Customer experience}

Untuk menarik perhatian pelanggan, perusahaan harus dapat mengetahui gambaran seperti apa yang dialami oleh pelanggan selama proses pembelian produk agar dapat memberikan kenyamanan terhadap pelanggan. Menurut Izogo (2018), customer experience secara beragam didefinisikan sebagai gambaran keseluruhan dari semua petunjuk yang dirasakan pelanggan dalam proses pembelian. Petunjuk dari gambaran yang diberikan pelanggan melalui pengalaman yang dirasakan sangat penting bagi perusahaan. Petunjuk dan gambaran itu sendiri berupa tanggapan pelanggan terdiri dari kognitif, afektif, dan fisik. Tanggapan pelanggan dari layanan kognitif berperan untuk memberikan pengetahuan tentang suatu produk, layanan afektif berasal dari perasaan atau emosi dalam hal ini lebih ke sifat suka atau tidak suka pelanggan selama proses interaksi pembelian, dan layanan fisik dapat dilihat dari semua yang tersedia secara fisik di sekitar lokasi perusahaan. Dalam penelitian Bustamante (2017), pengalaman pelanggan dalam toko ritel yang mencakup tanggapan pelanggan bersifat internal mendorong layanan (kognitif, afektif, dan fisik) dan interaksi sosial pelanggan. Selama proses pembelian terhadap suatu produk, interaksi pelanggan melibatkan berbagai aspek, yaitu aspek rasional yang harus memiliki pertimbangan yang logis pada suatu produk, aspek emosional yang didasarkan pada perasaan atau sikap seseorang dalam bereaksi pada produk, aspek sensorik yang didasarkan pada kemampuan pelanggan untuk memahami simbol-simbol tertulis, aspek fisik yang berhubungan dengan tempat produk, dan aspek spiritual yang merupakan bagian dari kejujuran manfaat suatu produk yang dijual. Menurut Verhoef (2009), customer experience bersifat pribadi dan menyiratkan keterlibatan pelanggan pada tingkat yang berbeda dalam aspek rasional, emosional, sensorik, fisik, dan spiritualnya.

Penggunaan produk harus mempunyai nilai tambah yang menambah pengetahuan dari setiap pengunaan fitur produk dengan pengetahuan dari fungsi produk yang ditawarkan diharapkan bisa menarik perhatian pelanggan. Menurut Nasermoadeli (2013), experience adalah ketika seorang pelanggan mendapatkan sensasi atau pengetahuan yang dihasilkan dari beberapa tingkat interaksi dengan berbagai elemen yang diciptakan oleh penyedia layanan. Sensasi atau pengetahuan yang didapat tersebut akan secara otomatis tersimpan dalam memori pelanggan. Perusahaan harus dapat memberikan pengalaman yang baik berupa interaksi secara langsung atau tidak langsung yang diperoleh dari proses pelayanan produk atau jasa yang diberikan kepada pelanggan sehingga mendorong kognitif, emosi dan respon pelanggan. Menurut Garg (2012), customer experience didefinisikan sebagai pengalaman langsung dan tidak langsung dari proses layanan, organisasi, fasilitas, bagaimana pelanggan berinteraksi dengan layanan perusahaan dan pelanggan lainnya yang pada akhirnya menciptakan kognitif, emosi, dan respon pelanggan serta pengalaman yang tak terlupakan. 


\section{Customer satisfaction.}

Perusahaan selalu berusaha memberikan kualitas produk layanan terbaik khususnya pada awal proses interaksi pembelian agar dapat membentuk kesan emosi pelanggan yang positif karena hal tersebut merupakan salah satu faktor penting dari kesuksesan perusahaan. Menurut Mei (2017), customer satisfaction, didefinisikan sebagai reaksi emosional positif setelah pembelian produk atau layanan. Pada umumnya reaksi dari pelanggan diketahui saat perusahaan melakukan evaluasi produk dimana hal tersebut dapat meningkatkan kualitas produk layanan dan menimbulkan pengalaman yang menyenangkan dari upaya memenuhi kebutuhan serta harapan pelanggan. Menurut Zeithaml (2011), kepuasan atau ketidakpuasan adalah evaluasi produk atau layanan yang ditawarkan untuk memenuhi kebutuhan atau harapan pelanggan. Cara singkat mengetahui bilamana konsumen menyukai produk atau tidak adalah dengan melihat ekspresi mereka pada saat layanan diberikan. Menurut Kant (2017), pada saat melakukan pembelian sebagian besar dapat dilihat dari ekspresi konsumen menyukai atau tidak menyukai layanan yang diberikan. Perusahaan melakukan segala upaya yang terbaik untuk menciptakan kesan pengalaman bagi pelanggan atas suatu produk yang ditawarkan sehingga menghasilkan reaksi psikologis dan persepsi pelanggan yang positif. Menurut George (2014), customer satisfaction adalah hasil kolektif dari persepsi, evaluasi, dan reaksi psikologis terhadap pengalaman selama mengkonsumsi suatu produk.

Perusahaan harus menguji dan memperhatikan produk sebelum menawarkan kepada konsumen agar manfaat produk yang ditawarkan saat diterima konsumen sesuai dengan kinerja produknya karena konsumen banyak berharap dari kinerja produk yang diterimanya. Menurut Kotler (2009), customer satisfaction atau kepuasan adalah perasaan senang atau kecewa seseorang yang timbul karena membandingkan kinerja yang dipersepsikan produk (atau hasil) terhadap ekpektasi mereka. Proses penilaian produk layak atau tidaknya produk tersebut di pasarkan oleh perusahaan wajib di lakukan supaya saat di pasarkan manfaat produk sesuai dengan standart kualitas yang ditawarkan. Menurut Worodiyanti (2016), customer satisfaction merupakan respon atau penilaian konsumen terhadap kinerja barang atau jasa yang mereka konsumsi dimana hasil yang diterima itu paling tidak harus sama dengan harapan konsumen. Setelah perusahaan menguji produk kualitasnya berfungsi dengan baik. Diwaktu yang sama perusahaan akan memperoleh keuntungan ketika konsumen merasa puas saat menerima layanan produk dan kinerja produk itu sesuai dengan keinginan mereka, jadi kinerja produk merupakan faktor penting untuk membuat pelanggan setia. Menurut Ferrel (2010), pelanggan yang puas akan menjadi setia, atau bahkan menganjurkan sebuah organisasi, memiliki reaksi minimal untuk perubahan harga, dan mengurangi kemungkinan untuk beralih ke pesaing.

\section{Loyalitas pelanggan}

Tujuan perusahaan melakukan evaluasi produk baik barang maupun jasa adalah untuk dapat mempertahankan loyalitas pelanggan. Jika dapat mempertahankan loyalitas pelanggan, hal ini akan menjadi suatu keuntungan bagi perusahaan, khususnya jika pelanggan setia terhadap suatu merek dari suatu produk. Menurut Jung (2013), loyalitas adalah sikap sebagai evaluasi yang baik yang diadakan dengan kekuatan dan stabilitas yang cukup untuk mendorong tanggapan berulang kali menguntungkan untuk barang atau jasa suatu merek. Perusahaan sangat membutuhkan pelanggan yang loyal karena banyak manfaat yang diterima terutama pelanggan yang loyal akan aktif menyampaikan produk yang dipakainya kepada orang-orang terdekatnya. Menurut Sawitri (2019), pelanggan yang loyal adalah pelanggan yang melakukan pembelian ulang, membeli dari berbagai lini produk dari suatu merek yang sama, merekomendasikan merek tersebut kepada orang lain, dan juga memiliki kekebalan terhadap penawaran produk pesaing.

Perusahaan harus berusaha menjaga kualitas produknya agar pelanggan tetap mempertahankan dan meningkatkan frekuensi pembelian pada produk jasa. Menurut Semuel dan Wibisono (2019), menyatakan kesetiaan adalah perilaku yang positif dan berhubungan dengan level pembelian kembali yang dilakukan oleh pelanggan terhadap suatu produk atau jasa secara tetap. Salah satu karakteristik pelanggan yang loyal adalah merekomendasikan produk atau jasa yang dipakainya dari sebuah merek perusahaan hal ini merupakan bagian dari promosi yang akan meningkatkan profit bagi perusahaan. Maka tidak heran loyalitas pelanggan memainkan peran penting dalam kesuksesan perusahaan. Menurut Li (2012), pelanggan yang setia memberikan perusahaan sumber pendapatan yang konsisten dari meningkatnya pembelian ulang dan pengurangan biaya promosi sehingga meningkatkan profitabilitas. 


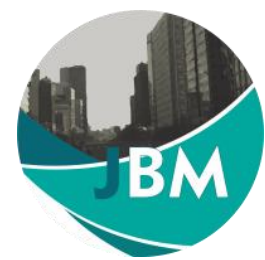

\section{Hubungan customer experience terhadap loyalitas pelanggan.}

Perusahaan selalu berupaya memberikan pengalaman yang berbeda dari pesaingnya dengan memberikan layanan produk jasa seperti AC yang sejuk, aroma ruangan yang wangi, dan keramahan dari staf sehingga membentuk kesan pengalaman yang tak terlupakan bagi pelanggan. Timbulnya kesan pengalaman positif diharapkan mampu meningkatkan loyalitas pelanggan. Menurut Wang (2010), experience yang telah dirasakan pelanggan selama mengkonsumsi suatu produk atau layanan mempunyai peranan sebagai salah satu faktor kunci utama yang berpengaruh signifikan terhadap customer loyalty. Dalam memberikan produk layanan terbaik, ada beberapa yang harus diperhatikan seperti perkembangan trend pasar yang sedang banyak diminati pada industri jasa pendidikan informal. Hal lain yang wajib diperhatikan oleh perusahaan adalah delivery produknya sesuai dengan ekspektasi pelanggan sebagai upaya menimbulkan loyalitas pelanggan pada produk jasa yang ditawarkan. Menurut Senjaya (2013), customer experience yang baik didapat dari pemahaman atas ekspektasi pelanggan, delivery produk yang tepat pada setiap kesempatan, dan berbagai faktor lainnya akan menimbulkan loyalitas. Hasil penelitian Hijjah dan Ardiansari (2015) menunjukkan bahwa customer experience dan customer value mempunyai pengaruh terhadap customer loyalty secara parsial. Selanjutnya hasil penelitian Azhari (2015) pada pelanggan KFC Kawi Malang, juga menunjukkan bahwa customer experience mempunyai pengaruh signifikan terhadap kepuasan pelanggan dan loyalitas pelanggan secara parsial. Berdasar uraian di atas, maka hipotesis pertama dalam penelitian ini adalah sebagai berikut:

$\mathrm{H}_{1}$ : Customer experience berpengaruh positif dan signifikan terhadap loyalitas pelanggan.

\section{Hubungan customer experience terhadap customer satisfaction.}

Agar perusahaan semakin berkembang dan mencapai visi misi perusahaan, maka perusahaan harus memberikan totalitas produk layanan yang menyeluruh dan customer experience berperan penting dalam hal tersebut. Oleh sebab itu customer experience harus benar-benar diperhatikan setiap saat karena dapat dapat meningkatkan customer satisfaction. Menurut Meesala dan Paul (2018), pelanggan yang melakukan beberapa kali pembelian terhadap produk menjadi pengalaman mereka dari waktu ke waktu selanjutnya akan mengarah pada customer satisfaction. Perusahaan melakukan berbagai strategi pemasaran seperti inovasi produk untuk menciptakan pengalaman yang baik dan memberikan kepuasan dalam setiap produk. Menurut Ali (2018), bagi penyedia layanan untuk bersaing, layanan mereka harus menciptakan berupa pengalaman pelanggan yang positif dan layanan mereka harus menghasilkan customer satisfaction.

Untuk sukses tidak hanya di pasar lokal tetapi juga di pasar global, perusahaan harus mampu membuktikan kualitas produk, dimana dapat dibuktikan melalui respon pengalaman yang menyenangkan dengan melalui penggunaan produk layanan jasa yang selalu di update karena tren pasar jasa yang bersifat dinamis. Menurut Salim (2015), pada dasarnya customer experience bagian dari penciptaan kepuasaan pelanggan melalui pengalaman, dan perusahaan yang mampu memberikan pengalaman yang tepat untuk konsumen akan sukses di pasar global, dalam hal ini dapat meningkatkan kepuasan konsumen. Perusahaan sangat bergantung pada customer experience bertujuan untuk menjaga perubahan perilaku pelanggan agar tidak berpaling ke pesaing dan berfungsi mempertahankan customer satisfaction. Menurut Nasution (2014), adanya customer experience dapat mempengaruhi terjadinya perubahan perilaku pelanggan salah satunya kepuasan yang dialami pelanggan. Hasil Penelitian Mantala dan Firdaus (2016) menunjukkan bahwa customer experience mempunyai pengaruh terhadap customer satisfaction pada pengguna smartphone android pada mahasiswa Politeknik Negeri Banjarmasin secara parsial. Begitu juga halnya dengan hasil penelitian Tuwisna (2017) menunjukkan bahwa customer value dan customer experience mempunyai pengaruh secara parsial terhadap customer satisfaction pada PT. Bank Mandiri (Persero) KCP Sabang. Berdasar uraian beberapa hasil penelitian di atas, maka hipotesis kedua dalam penelitian ini adalah sebagai berikut:

$\mathrm{H}_{2}$ : Customer experience berpengaruh positif dan signifikan terhadap customer satisfaction. 


\section{Hubungan customer satisfaction terhadap loyalitas pelanggan.}

Keefektifan dan ketidakefektifan pemasaran perusahaan dapat dilihat dari tingkat kepuasan dan ketidakpuasan pelanggan. Salah satu faktor keberhasilan untuk dapat bertahan dalam persaingan usaha di bidang jasa adalah meningkatkan kinerja staf perusahan agar mendapatkan customer satisfaction yang berdampak pada peningkatan loyalitas pelanggan. Menurut Tu (2012), pengukuran kepuasan maupun ketidakpuasan pelanggan terhadap suatu produk maupun merek merupakan indikator yang penting dari loyalitas pelanggan. Perusahaan rutin mengevaluasi produk bertujuan untuk memperbaiki kelemahan kualitas produk supaya meningkatkan customer satisfaction diikuti dengan peningkatan loyalitas pelanggan. Menurut Deng (2010), peningkatan kepuasan bagi konsumen secara terus menerus akan meningkatkan loyalitas pelanggan. Hasil dari loyalitas pelanggan dilihat dari pelanggan merekomendasikan produk jasa kepada orang lain yang dapat memberi keuntungan pada perusahaan. Menurut Coll (2013), kepuasan yang muncul pada diri konsumen menimbulkan loyalitas sehingga menguntungkan bagi perusahaan. Hasil penelitian Arianto (2016) menunjukkan bahwa customer satisfaction, brand trust, dan customer feedback mempunyai pengaruh terhadap customer loyalty pada perusahaan mobil Suzuki secara parsial. Selanjutnya hasil penelitian Kusumawati (2015) menunjukkan bahwa kepuasan konsumen mempunyai pengaruh terhadap loyalitas pelanggan secara parsial. Begitu juga halnya dengan penelitian Alfin (2017) menunjukkan bahwa kepuasan pelanggan memiliki pengaruh terhadap loyalitas pelanggan secara parsial. Berdasarkan uraian di atas, maka hipotesis ketiga adalah penelitian ini adalah sebagai berikut:

$\mathrm{H}_{3}$ : Customer satisfaction berpengaruh positif dan signifikan terhadap loyalitas pelanggan.

\section{Customer satisfaction sebagai pemediasi antara customer experience dengan loyalitas pelanggan.}

Bentuk penerapan dari produk jasa yang telah dilakukan perusahaan dilihat dari pelanggan yang menemukan pengalaman yang menyenangkan terhadap jasa sehingga menimbulkan kenangan yang sulit dilupakan. Hal tersebut dengan sendirinya akan menciptakan customer satisfaction. Menurut Banjarnahor (2017), customer experience adalah suatu proses, strategi dan implementasi perusahaan dalam mengelola pengalaman pelanggan terhadap produk atau layanan yang mampu menjawab kebutuhan pelanggan dan menciptakan customer satisfaction, dimana pelanggan merasakan pengalaman positif yang tidak terlupakan (memorable experience), sehingga selalu mengingat layanan atau produk tersebut ketika membutuhkannya. Hasil penelitian Wardhana (2016) dengan analisis kuantitatif menunjukkan bahwa kepuasan pelanggan memediasi hubungan pengalaman pelanggan dengan loyalitas konsumen mie rampok tahanan Surabaya. Selain itu, hasil penelitian Hardiyanti (2017) menunjukkan bahwa kepuasan pelanggan memediasi hubungan antara kualitas layanan, customer experience, dan kepercayaan terhadap loyalitas pada PT PELNI cabang Semarang. Berdasarkan uraian di atas, maka hipotesis keempat adalah sebagai berikut: $\mathrm{H}_{4}$ : Customer satisfaction memediasi hubungan antara customer experience dengan loyalitas pelanggan.

Gambar 1. Kerangka Penelitian

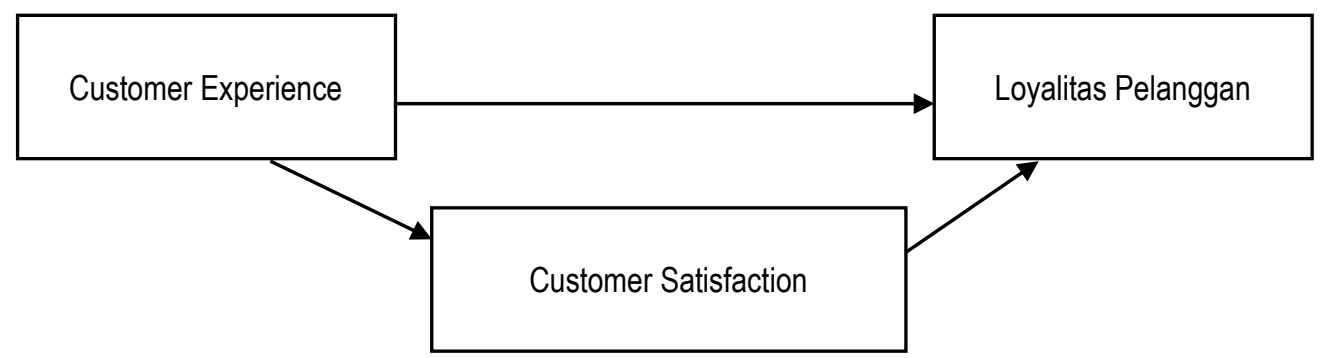




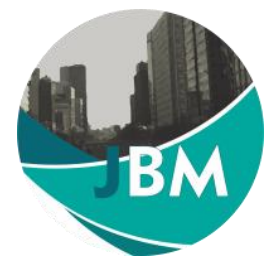

\section{Metode Penelitian}

Dalam penelitian ini, peneliti menggunakan metode penelitian deskriptif kuantitatif. Pendekatan dalam penelitian ini adalah pendekatan kuantitatif. Populasi dalam penelitian ini adalah seluruh pelanggan yang pernah dan masih menjadi siswa-siswi Ganesha Operation Medan. Teknik pengambilan sampel yang digunakan dalam penelitian ini adalah quota sampling. Jumlah sampel yang ditetapkan 150 responden.

Teknik analisis data yang digunakan dalam penelitian ini adalah analisis structural equation modeling-partial least squares (SEM-PLS) dengan menggunakan software SmartPLS. SEM dibagi menjadi dua jenis, yakni covariance-based SEM (CB-SEM) dan variance-based SEM atau partial least squares (SEM-PLS). SEM-PLS yang diterapkan dalam penelitian ini mengacu pada tahap evaluasi reliability yang terbagi menjadi dua tahap, yaitu evaluasi indicator reliability, dan evaluasi internal consistency reliability dimana evaluasi reliability ini dilakukan untuk melihat apakah data yang digunakan di dalam penelitian ini konsisten atau tidak, karena hal ini dapat berpengaruh besar terhadap output data yang akan diuji selanjutnya, kemudian tahap selanjutnya dilakukan evaluasi validitas data dengan menggunakan convergent validity dan discriminant validity dimana evaluasi ini bertujuan untuk melihat apakah variabel yang digunakan didalam penelitian ini akurat dalam melakukan pengolahan data, berikutnya dilakukan uji path coefficient dan coefficient of determination, dan yang terakhir adalah menggunakan metode bootstrapping untuk mencari nilai t-statistics yang penggunaannya adalah untuk pengujian hipotesis.

Berikut adalah tabel dengan variabel dan indikator penelitian.

Tabel 1. Indikator Penelitian

\begin{tabular}{ll}
\hline Variabel & Indikator \\
\hline Customer Experience (X1) & 1) Sensory experience \\
& 2) Emotional experience \\
& 3) Social experience \\
\hline \multirow{3}{*}{ Customer Satisfaction (X2) } & 1) Expectations \\
& 2) Subjective Disconfirmation, \\
& 3) Performance Outcomes, \\
\hline Loyalitas Pelanggan (Y) & 1) Word of Mouth Promotion \\
& 2) Future Repurchase Intention \\
& 3) Price Sensitive \\
\hline
\end{tabular}

Hasil

Berdasarkan hasil penyebaran kuesioner, diperoleh karaketeristik berdasarkan usia dimana pelanggan berusia 15 - 17 tahun mendominasi sebesar $65.3 \%$. Hal tersebut terjadi karena pelanggan jasa bimbingan belajar adalah siswa-siswi SMP dan SMA. Karakteristik pelanggan berdasarkan jenis kelamin didominasi oleh perempuan sebesar $71.4 \%$ dikarenakan para siswi lebih banyak tertarik untuk bimbingan belajar. Karakteristik pelanggan berdarkan tingkat pendidikan didominasi oleh pelajar SMA sebesar $92.7 \%$ dikarenakan mereka lebih banyak membutuhkan bimbingan belajar dalam mempersiapkan diri untuk lulus PTN dan sekolah kedinasan favorit. Para pelajar yang diteliti dalam penelitian ini ditemukan $37 \%$ yang sudah berlangganan dibawah 1 tahun, $36 \%$ selama 1 - 2 tahun, $17 \%$ selama $3-4$ tahun, dan $10 \%$ diatas 4 tahun. Hal tersebut menunjukkan bahwa banyak para pelajar memiliki pengalaman bimbingan di Ganesha Operation dikarenakan mereka puas dan bahkan loyal terhadap jasa pelayanan bimbingan belajar. 
Tabel 2. Hasil Profil Responden

\begin{tabular}{|c|l|c|c|}
\hline No & $\begin{array}{l}\text { Karakteristik } \\
\text { Responden }\end{array}$ & $\begin{array}{l}\text { Jumlah } \\
\text { (orang) }\end{array}$ & $\begin{array}{l}\text { Persentase } \\
\text { (\%) }\end{array}$ \\
\hline \multirow{5}{*}{1} & Jenis Kelamin & & \\
\cline { 2 - 4 } & a. Laki-laki & 43 & 28.6 \\
\cline { 2 - 4 } & b. Perempuan & 107 & 71.4 \\
\cline { 2 - 4 } & Total & 150 & 100 \\
\hline \multirow{5}{*}{2} & Usia & & \\
\cline { 2 - 4 } & a.12-14 Tahun & 7 & 4.7 \\
\cline { 2 - 4 } & b. 15-17 Tahun & 98 & 65.3 \\
\cline { 2 - 4 } & c. $>17$ Tahun & 45 & 30 \\
\cline { 2 - 4 } & Total & 150 & 100 \\
\hline \multirow{5}{*}{3} & Tingkat Pendidikan & & \\
\cline { 2 - 4 } & a. SMP & 11 & 7.3 \\
\cline { 2 - 4 } & b. SMA & 139 & 92.7 \\
\cline { 2 - 4 } & Total & 150 & 100 \\
\hline \multirow{4}{*}{4} & Lama Bimbingan & & \\
\cline { 2 - 4 } & a. $<1$ Tahun & 55 & 37 \\
\cline { 2 - 4 } & b. 1-2 Tahun & 54 & 36 \\
\cline { 2 - 4 } & c. 3-4 Tahun & 26 & 17 \\
\cline { 2 - 4 } & d. > 4 Tahun & 15 & 10 \\
\cline { 2 - 4 } & Total & 150 & 100 \\
\hline \multirow{3}{*}{ Sumber: Data Primer yang diolah, 2020 } & \\
\cline { 2 - 4 } & & & \\
\hline
\end{tabular}

Deskripsi tanggapan responden sebanyak 150 orang Ganesha Operation terhadap item pernyataan customer experience sebanyak 10 item, customer satisfaction sebanyak 7 item, dan loyalitas pelanggan sebanyak 9 item. Berdasarkan hasil penyebaran kuesioner, diperoleh tanggapan responden pada customer experience dimana nilai rata-rata terendah terdapat pada item "aroma ruangan di Ganesha Operation Medan wangi". Hal ini mengindikasikan aroma ruangan tempat belajar kurang wangi dikarenakan dalam setiap kelas masih kurang pewangi ruangan dan kondisi toilet yang tidak punya pewangi. Selain itu nilai tertinggi terdapat pada item "Ganesha Operation Medan menampilkan cahaya ruangan yang terang" dan "AC di Ganesha Operation sejuk". Hal tersebut mengindikasi bahwa fasilitas yang telah diberikan kepada pelanggan sudah sesuai dengan fasilitas yang ditawarkan dan tidak hanya sekedar janji dalam promosi. Berdasarkan hasil penyebaran kuesioner, diperoleh tanggapan responden pada customer satisfaction dimana nilai rata-rata terendah terdapat pada item "Mutu layanan pengajar bimbingan belajar di Ganesha Operation Medan lebih dari yang saya harapkan". Hal tersebut mengindikasi bahwa layanan para pengajar dalam perusahaan ini sedang dikarenakan kebutuhan siswa kurang terlayani khususnya dalam jasa TST (tutorial service time). Selain itu nilai tertinggi terdapat pada item "Informasi pendidikan yang terupdate saya dapatkan di bimbingan belajar Ganesha Operation". Hal ini mengindikasi bahwa informasi seputar pendidikan teranyar di perusahaan ini tinggi dan tepat sasaran untuk para siswa. Berdasarkan hasil penyebaran kuesioner, diperoleh tanggapan responden pada customer loyalty dimana nilai rata-rata terendah terdapat pada "saya sering menginformasikan diri saya bahwa saya sedang berada di Ganesha Operation melalui jejaring sosial media". Hal ini mengindikasi bahwa loyalitas para siswa terhadap GO dalam publikasi di media sosial masih kurang dikarenakan mereka lebih tertarik memberitahukan kegemaran mereka di media sosial. 
Gambar 1. Diagram Jalur Berdasarkan Nilai Loading Faktor

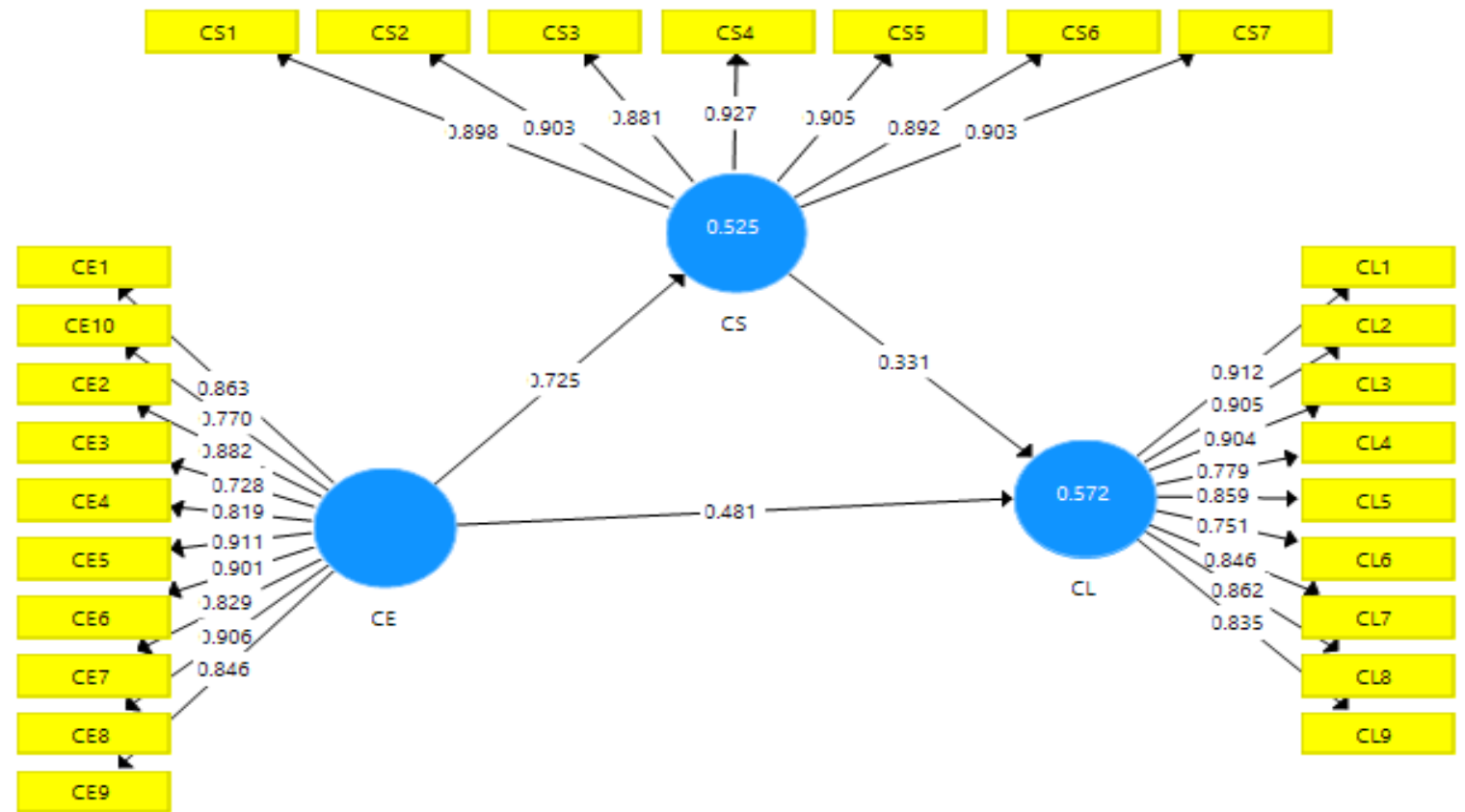

Sumber: Hasil olah data SmartPLS 3.0 Program Processing, 2020

Berdasarkan pengujian validitas loading faktor pada Gambar 1, seluruh nilai loading $>0,7$, yang berarti telah memenuhi syarat validitas berdasarkan nilai loading. Selanjutnya dilakukan pengujian validitas berdasarkan nilai average variance extracted (AVE).

Tabel 3. Hasil Pengujian Validitas berdasarkan AVE

\begin{tabular}{cc} 
& $\begin{array}{c}\text { Average variance Extracted } \\
\text { (AVE) }\end{array}$ \\
CE & 0,718 \\
CL & 0,726 \\
CS & 0,812 \\
\hline
\end{tabular}

Sumber: Hasil olah data SmartPLS 3.0 Program Processing, 2020

Nilai AVE yang disarankan adalah di atas 0,5 (Sholihin, 2013). Diketahui seluruh nilai AVE > 0,5, yang berarti telah memenuhi syarat validitas berdasarkan AVE. Selanjutnya dilakukan pengujian reliabilitas berdasarkan nilai composite reliability (CR).

Tabel 4. Hasil Pengujian Reliabilitas berdasarkan Composite Reliability (CR)

\begin{tabular}{lc} 
& Composite Reliability \\
CE & 0,962 \\
CL & 0,960 \\
CS & 0,968 \\
\hline
\end{tabular}

Sumber: Hasil olah data SmartPLS 3.0 Program Processing, 2020 
Nilai CR yang disarankan adalah di atas 0,7 (Sholihin, 2013). Diketahui seluruh nilai CR $>0,7$, yang berarti telah memenuhi syarat reliabilitas berdasarkan $\mathrm{CR}$. Selanjutnya dilakukan pengujian reliabilitas berdasarkan nilai cronbach's alpha (CA).

Tabel 5. Hasil Pengujian Reliabilitas berdasarkan Cronbach's Alpha (CA)

\begin{tabular}{cc} 
& Cronbach's Alpha \\
$\mathrm{CE}$ & 0,956 \\
$\mathrm{CL}$ & 0,952 \\
$\mathrm{CS}$ & 0,961 \\
\hline ber: Hasil olah data SmartPLS 3.0 Program Processing, 2020
\end{tabular}

Nilai CA yang disarankan adalah di atas 0,7 (Sholihin, 2013). Diketahui seluruh nilai CA $>0,7$, yang berarti telah memenuhi syarat reliabilitas berdasarkan cronbach's alpha. Selanjutnya dilakukan pengujian validitas diskriminan dengan pendekatan Fornell-Larcker. Tabel 5 disajikan hasil pengujian validitas diskriminan.

Tabel 6. Hasil Pengujian Validitas Diskriminan

\begin{tabular}{|c|c|c|c|}
\hline & & $\mathrm{CL}$ & CS \\
\hline CE & 0,848 & & \\
\hline $\mathrm{CL}$ & 0,721 & 0,852 & \\
\hline CS & 0,725 & 0,680 & 0,901 \\
\hline
\end{tabular}

Pada pengujian validitas diskriminan, nilai akar kuadrat AVE dari suatu variabel laten, dibandingkan dengan nilai korelasi antara variabel laten tersebut dengan variabel laten lainnya. Diketahui nilai akar kuadrat AVE dari untuk setiap variabel laten, lebih besar dibandingkan nilai korelasi antara variabel laten tersebut dengan variabel laten lainnya, sehingga disimpulkan telah memenuhi syarat validitas diskriminan.

Tabel 7. Hasil Nilai Koefisien Jalur dan P-Value

\begin{tabular}{rrrrrr} 
& $\begin{array}{c}\text { Original } \\
\text { Sample } \\
(\mathrm{O})\end{array}$ & $\begin{array}{c}\text { Sample } \\
\text { Mean } \\
(\mathrm{M})\end{array}$ & $\begin{array}{l}\text { Standard } \\
\text { Deviation } \\
(\text { STDEV) }\end{array}$ & $\begin{array}{c}\text { T Statistics } \\
(\text { (O/STDEV) }\end{array}$ & P Values \\
$\mathrm{CE} \longrightarrow \mathrm{CL}$ & 0,481 & 0,474 & 0,163 & 2,953 & 0,003 \\
$\mathrm{CE} \longrightarrow \mathrm{CS}$ & 0,725 & 0,732 & 0,090 & 8,084 & 0,000 \\
$\mathrm{CS} \longrightarrow \mathrm{CL}$ & 0,331 & 0,334 & 0,165 & 2,009 & 0,045 \\
\hline
\end{tabular}

Sumber: Hasil olah data SmartPLS 3.0 Program Processing, 2020

Berdasarkan hasil pada Tabel 7 diperoleh hasil:

1. Customer experience berpengaruh positif terhadap loyalitas pelanggan, dengan nilai koefisien jalur 0,481 dan signifikan, dengan nilai $P$-Values $0,003<0,05$.

2. Customer experience berpengaruh positif terhadap customer satisfaction, dengan nilai koefisien jalur 0,725 dan signifikan, dengan nilai $P$-Values $0,000<0,05$.

3. Customer satisfaction berpengaruh positif terhadap, loyalitas pelanggan dengan nilai koefisien jalur 0,331 dan signifikan, dengan nilai $P$-Values $0,045<0,05$.

Tabel 8. Hasil Nilai Koefisien Determinasi

\begin{tabular}{cc}
\hline \multicolumn{1}{c}{ R Square } \\
$\mathrm{CL}$ & 0,572 \\
$\mathrm{CS}$ & 0,525 \\
\hline Sumber: Hasil olah data SmartPLS 3.0 Program Processing, 2020
\end{tabular}




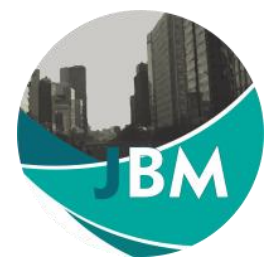

Berdasarkan Tabel 8, diketahui nilai koefisien determinasi untuk variabel customer satisfaction adalah 0,525, yang berarti customer experience mampu mempengaruhi customer satisfaction sebesar $52,5 \%$. Sementara diketahui nilai koefisien determinasi dari variabel loyalitas pelanggan adalah 0,572. Nilai tersebut dapat diartikan variabel customer experience dan customer satisfaction mampu mempengaruhi loyalitas pelanggan sebesar $57,2 \%$.

\section{Uji Signifikansi Pengaruh Tidak Langsung (Indirect Effect)}

Selanjutnya dilakukan pengujian pengaruh tidak langsung (indirect effect), yakni menguji apakah customer satisfaction signifikan dalam memediasi hubungan customer experience terhadap loyalitas pelanggan. Tabel 9 , disajikan hasil pengujian signifikansi pengaruh tidak langsung.

Tabel 9. Hasil Pengujian Mediasi (Pengaruh Tidak Langsung)

\begin{tabular}{cccccc} 
& $\begin{array}{c}\text { Original } \\
\text { Sample (O) }\end{array}$ & $\begin{array}{c}\text { Sample Mean } \\
(\mathrm{M})\end{array}$ & $\begin{array}{l}\text { Standard } \\
\text { Deviation } \\
\text { (STDEV })\end{array}$ & $\begin{array}{c}\text { T Statistics } \\
(\text { (O/STDEV })\end{array}$ & P Values \\
\hline CE $>$ CS $>C L$ & 0.493 & 0.500 & 0.117 & 4.224 & 0.000 \\
\hline
\end{tabular}

Sumber: Hasil olah data SmartPLS 3.0 Program Processing, 2020

Berdasarkan hasil pada Tabel 9, diketahui pengaruh tidak langsung customer experience terhadap loyalitas pelanggan, melalui customer satisfaction sebesar 0,493 dengan nilai $P$-Values $0,000<0,05$, maka disimpulkan customer satisfaction signifikan sebagai pemediasi hubungan antara customer experience terhadap loyalitas pelanggan.

\section{Pembahasan}

Penelitian ini menunjukkan bahwa melalui analisis structural equation modeling-partial least squares (SEMPLS) diperoleh hasil yang menunjukkan adanya hubungan positif antara customer experience dengan customer satisfaction dengan nilai koefisien jalur 0,725 dan berpengaruh signifikan, dengan nilai $P$-Values $0,000<0,05$. Hasil tersebut menunjukkan bahwa semakin tinggi customer experience yang dirasakan oleh para siswa maka semakin tinggi juga tingkat kepuasan pelanggan. Para siswa akan merasa dengan adanya customer experience maka akan semakin menambah nilai suatu perusahaan jasa bimbingan belajar. Jadi, pelaku usaha jasa pendidikan non formal harus memberikan pengalaman positif kepada baik kepada pelanggan maupun konsumen, sehingga mereka merasa puas dan berniat melakukan pembelian berulang. Hasil penelitian ini sejalan dengan penelitian oleh (Wardhana, 2016) yang menyatakan bahwa customer experience memiliki pengaruh positif terhadap kepuasan pelanggan. Selain itu penelitian ini juga sesuai dengan penelitian yang dilakukan oleh (Mantala dan Firdaus, 2016) dimana terdapat pengaruh secara parsial antara variabel customer experience terhadap customer satisfaction pada pengguna smartphone android (Studi pada Mahasiswa Politeknik Negeri Banjarmasin.

Penelitian ini menunjukkan bahwa melalui structural equation modeling-partial least squares (SEM-PLS) diperoleh hasil bahwa customer experience berpengaruh positif terhadap customer loyalty , dengan nilai koefisien jalur 0,481 dan signifikan, dengan nilai $P$-Values $0,003<0,05$. Hal tersebut menunjukkan bahwa semakin tinggi customer experience yang dirasakan para siswa, maka semakin tinggi juga tingkat loyalitas para siswa terhadap layanan bimbingan belajar di Ganesha Operation. Jadi, pelaku usaha jasa pendidikan harus memberikan dan menciptakan pengalaman positif agar mereka tetap setia untuk bimbingan belajar di tempat tersebut. Hasil penelitian sejalan dengan penelitian (Wardhana, 2016) menyatakan bahwa adanya hubungan positif antara customer experience terhadap loyalitas pelanggan.

Hasil penelitian ini menunjukkan bahwa melalui structural equation modeling-partial least squares (SEM-PLS) diperoleh hasil bahwa customer satisfaction berpengaruh positif dan signifikan terhadap customer loyalty dengan nilai koefisien jalur 0,331 dan dengan nilai $P$-Values 0,045 <0,05. Hasil tersebut menunjukkan bahwa apabila semakin 
tinggi tingkat kepuasan pelanggan, semakin tinggi tingkat loyalitas pelanggan Ganesha Operation. Hal tersebut menjelaskan bahwa loyalitas pelanggan Ganesha Operation dipengaruhi oleh kepuasan yang dirasakan oleh para siswa. Pengalaman yang diberikan oleh Ganesha Operation dapat menghasilkan pelanggan kepuasan pelanggan, dan mampu mendorong pelanggangbtersebut untuk setia. Pelanggan yang puas biasanya tetap setia dalam waktu yang lebih lama dan membicarakan hal - hal baik tentang produk jasa yang didapatkan kepada orang lain (Kotler dan Keller, 2009). Hasil penelitian sejalan dengan (Arianto, 2016) yang menyatakan bahwa secara parsial kepuasan pelanggan berpengaruh positif terhadap loyalitas pelanggan pada perusahaan mobil Suzuki.

\section{Kesimpulan}

Hasil penelitian menunjukkan bahwa customer experience berpengaruh positif dan signifikan terhadap customer loyalty, customer experience berpengaruh positif dan signifikan terhadap customer satisfaction, dan customer satisfaction berpengaruh positif dan signifikan terhadap customer loyalty. Selain itu, hasil penelitian juga menunjukkan bahwa diketahui pengaruh tidak langsung customer experience terhadap customer loyalty, melalui customer satisfaction maka disimpulkan customer satisfaction signifikan sebagai pemediasi hubungan antara customer experience terhadap loyalitas pelanggan.

Adapun saran pada perusahaan, diharapkan pihak Ganesha Operation lebih memperhatikan fasilitas yang diberikan kepada siswa dengan menyesuaikan gaya hidup remaja zaman milenia. Untuk dapat meningkatkan emotional experience, pihak Ganesha Operation dapat mengenalkan bahwa produknya memiliki kualitas yang sangat baik melalui media sosial yang diminati kalangan remaja seperti Instragram secara kontinu sehingga para siswa merasa bangga belajar di Ganesha Operation. Saran pada peneliti selanjutnya diharapkan meneliti objek penelitian lain seperti di bidang usaha perbankan ataupun manufaktur. Penelitian ini memiliki keterbatasan sampel dimana hanya dilakukan hanya Ganesha Operation Medan, sehingga disarankan penelitian mendatang untuk menambah jumlah sampel dan memperluas lokasi penelitian.

\section{Ucapan terima kasih}

Peneliti mengucapkan terima kasih kepada Kemenristek/BRIN (Kementerian Riset dan Teknologi/Badan Riset dan Inovasi Nasional) atas hibah Penelitian Dosen Pemula tahun anggaran 2020. Peneliti juga mengucapkan terima kasih kepada seluruh pihak yang telah membantu terlaksananya penelitian ini.

\section{Daftar Pustaka}

Alfin, R, M., dan Nurdin. (2017). Pengaruh Store Atmosphere Pada Kepuasan Pelanggan Yang Berimplikasi Pada Loyalitas Pelanggan. Jurnal Ecodemica, 1(2), 249-258.

Ali, F., Kim, G, W., Li, J., and Jeon, M, H. (2018). Make it Delightful: Customers' Experience, Satisfaction and Loyalty in Malaysian Theme Parks. Journal of Destination Marketing \& Management, 7, 1-11.

Arianto, S, P, J. (2016). Pengaruh Customer Satisfaction, Brand Trust, dan Customer Feedback Terhadap Customer Loyalty Pada Perusahaan Mobil Suzuki. Jurnal Al-Qardh, 1(5), 50-60.

Azhari, I, M., Fanani, D., dan Mawardi, K, M. (2015). Pengaruh Customer Experience Terhadap Kepuasan Pelanggan dan Loyalitas Pelanggan (Survei Pada Pelanggan KFC Kawi Malang). Jurnal Administrasi Bisnis, 28(1), 143-148.

Bps.(2016). [online]. Diakses dari https://se2016.bps.go.id/umkumb/index.php/metadata/.

Banjarnahor, J. (2017). Anteseden Customer Satisfaction dan Dampaknya Pada Purchase Intention, Jurnal Manajemen dan Pemasaran Jasa, 10 (1), 141-156.

Coll, F, S., Saumell, R, R., Garcia, S, J., and Roig. J, C, F. (2013). Airline Website Loyalty Formation and The Moderating Effects of Gender and Education. Service Business, 7(2), 255-274.

Deng, Z., Lu, Y., Wei, K.K., and Zhang, J. (2010). Understanding Customer Satisfaction and Loyalty: An Empirical Study Of Mobile Instant Messages In China . International Journal of Information Management, 30(4), 289-300. 
Dirbawanto, D.N., dan Endang, S. (2016). Pengaruh Customer Experience dan Brand Trust Terhadap Customer Loyalty. Management Analysis journal, 5(1), 70-76.

Ferrel, O.C., and Hartline, B. (2010). Marketing Stra-tegy. New York: Cengage Learning.

Garg, Ruchi, dan Zillur Rahman. (2012). Measuring Customer Experience In Banks: scale of Development and Validation. Journal of Modelling Management, 19(1), 87-177.

George, A. and Kumar, G.G. (2014). Impact of Service Quality Dimensions in Internet Banking on Customer Satisfaction. Decision, 41(1), 73-85.

Hardiyanti, Lien. (2017). Peran Kepuasan dalam memediasi Pengaruh Kualitas Layanan, Customer Experience, dan Kepercayaan terhadap Loyalitas.Skripsi. Universitas Negeri Semarang.

Hijjah, R., dan Ardiansari, A. (2015). Pengaruh Customer Experience dan Customer Value Terhadap Customer Loyalty Melalui Customer Satisfaction. Management Analysis Journal, 4(4), 281-288.

Izogo, E, E., Jayawardhena, C., and Kalu, U, O, A. (2018). Examining Customers' Experience With the Nigerian Bank Verification Number (BVN) Policy From The Perspective of A Dual-Lens Theory. International Journal of Emerging, 13(4), 709-730.

Jung, H.S., and Yoon, H.H. (2013). Do Employees' Satisfied Customers Respond With A Satisfactory Relationship? The Effects Of Employees' Satisfaction on Customers'Satisfaction and Loyalty In A Family Restaurant. International Journal of Hospitality, 34(1), 1-8.

Kant, R., and Jaiswal, D. (2017). Impact of Service Perceived Service Quality Dimensions on Customer Satisfaction An Empirical Study on Public Sector Banks in India. International Journal of Bank, 35(3), 411-430.

Kotler., dan Keller. (2009). Manajemen Pemasaran. Jakarta: Erlangga.

Kusumawati, D, A, D. (2015). Analisis Pengaruh Kepuasan Konsumen Terhadap Loyalitas Pelanggan Dengan Kualitas Produk Sebagai Variabel Mediasi. Jurnal Ekonomi dan Kewirausahaan, 15(2), 245-252.

Li, G. (2012). A Mediating Influence on Customer Loyalty: The Role Of Perceived Value. Journal of Management and Marketing Research, 7, 1-12.

Mantala. R., dan Firdaus, R, M. (2016). Pengaruh Customer Experience Terhadap Customer Satisfaction Pada Pengguna Smartphone Android (Studi pada Mahasiswa Politeknik Negeri Banjarmasin). Jurnal Wawasan Manajemen, 4(2), 153-164.

Meesala, A., And Paul, J. (2018). Service Quality, Consumer Satisfaction and Loyalty in Hospitals: Thinking For The Future. Journal of Retailing and Consumer Services. Journal of Retailing and Consumer Services, 40, 261-269.

Mei, J., Li, K., and Li, K. (2017). Customer Satisfaction Aware Optimal Multiserver Configuration for Profit Maximization in Cloud Computing. IEEE Transactions on Sustainable Computing, 2(1), 17-29.

Nasermoadeli, A., Kwek, L, C., and Farshad, M. (2013). Evaluating the Impact of Customer Experience on Repurchase Intention. International Journal of Business and Management, 8(6), 128-138.

Nasution, R. A., Sembada, A. Y., Miliani, L., Resti, N. D., dan Prawono, D. A., (2014). The Customer Experience Framework as Baseline for Strategy and Implementation in Services Marketing. Procedia - Social and Behavioral Sciences 148, $254-261$.

Salim, F, K., Catherine, and Andreani, F. (2015). Pengaruh Customer Experience Dan Kepercayaan Terhadap Kepuasan Konsumen Di TX Travel Klampis. Jurnal Hospitality dan Manajemen Jasa, 3(1), 322-340.

Sangadji, Etta Mamang dan Sopiah. (2013). Perilaku Konsumen - Pendekatan Praktis disertai Himpunan Jurnal Penelitian. Yogyakarta: Andi. 
Sawitri, D, T, A, G, I., dan Rahanatha, B, G. (2019). Pengaruh Green Marketing dan Brand Image Terhadap Loyalitas Pelanggan. E-Jurnal Manajemen, 8(8), 5267-5284.

Semuel, H., dan Wibisono, J.(2019). Brand Image, Customer Satisfaction dan Customer Loyalty Jaringan Supermarket Superindo Di Surabaya. Jurnal Manajemen Pemasaran, 13 (1), 27-34.

Senjaya, V., Semuel, H., dan Dharmayanti, D. (2013). Pengaruh Customer Experience Quality Terhadap Customer Satisfaction \& Customer Loyalty Di Kafe Excelso Tunjungan Plaza Surabaya: Perspektif B2C. Manajemen Pemasaran Petra, 1(1), 1-15.

Sholihin, M., dan Ratmono, D. (2013). Analisis SEM-PLS dengan WarpPLS 3.0. Yogyakarta: Andi.

Sindonews. (2019). [online]. Diakses dari https://edukasi.sindonews.com/berita/1378261/144/pendidikan-nonformalpenting-untuk-hadapi-dunia-industri?showpage=all.

Subagio, H., dan Saputra, R. (2012). Pengaruh Perceived Service Quality, Perceived Value, Satisfaction Dan Image Terhadap Customer Loyalty (Studi Kasus Garuda Indonesia). Jurnal Manajemen Pemasaran, 7(1), 42-51.

Terblanche, S. N. (2009). Customer Experience Interactions,Relationship and Corporate Reputation. Journal of General Management, 35(3), 5-17.

Tuwisna, Gadeng, T., dan Anggraini L (2017). Pengaruh Customer Value Dan Customer Experience Terhadap Customer Satisfaction Pada PT. Bank Mandiri (Persero) KCP Sabang. SEMDI UNAYA (pp. 494-506). Aceh: Universitas Abulyatamata.

Verhoef, P.C., Lemon, K.N., Parasuraman, A., Rog-geveen, A., Tsiros, M. and Schlesinger. (2009). Customer Experience Creation: Determi-nants, Dynamics and Management. Journal of Retailing, 85(1), 31-41..

Wang, X. (2010). Effect Of Consumption Experience On Brand And Loyalty: Research In The Repurchase Of Popular Entertainment Products". International Journal of Innovative Management, Information \& Production, 1(1), $97-$ 109

Wardhana, E. R. (2016). Pengaruh Customer Experience Terhadap Loyalitas Pelanggan Dengan Kepuasan Pelanggan Sebagai Variabel Intervening (Studi Pada Konsumen Mie Rampok Tahanan Surabaya). Jurnal IImu Manajemen, 4(3), 1-9.

Worodiyanti, N. W. M. (2016). Pengaruh Kualitas Produk, Harga, dan Kualitas Layanan Terhadap Kepuasan Konsumen di elladerma skin care malang. e-Journal, 5(1), 23-28.

Zeithaml, V.A., Bitner, M.J. and Gremler, D. D. (2011). Services Marketing: Integrating Customer Focus across the Firm. New Delhi: McGraw Hill. 